\title{
Predictors of Malignancy for Female Patients with Suspicious Nipple Discharge: A Retrospective Study
}

\author{
LIANG JIN ${ }^{1,2}$, LILING ZHU $^{1,2}$, SHUNRONG LI ${ }^{1,2}$, YINDUO ZENG ${ }^{1,2}$, \\ LIN HAIXIONG ${ }^{3}$, FENGXI SU ${ }^{1,2}$ and KAI CHEN ${ }^{1,2}$ \\ ${ }^{1}$ Guangdong Provincial Key Laboratory of Malignant Tumor Epigenetics and Gene Regulation, \\ ${ }^{2}$ Breast Tumor Center, and ${ }^{3}$ Department of Clinical Laboratory, Sun Yat-Sen University Memorial Hospital, \\ Sun Yat-Sen University, Guangzhou, P.R. China
}

\begin{abstract}
Background: Suspicious nipple discharge (ND) in females requires further treatment, including biopsy or selective duct excision. It is important to identify predictors of malignancy in female patients with suspicious ND. Materials and Methods: This retrospective study included patients with suspicious ND who underwent surgical treatment at our center between January 2007 and December 2014. Clinicopathological features were compared between patients with and without malignancy. We used a Chi-square test and a logistic regression model as the univariate and multivariate analysis for identification of predictors of malignancy. Results: A total of 334 patients were eligible and included. The median age of the study population was 45 (range $=19-81)$ years; $18.0 \%$ (60/334) of the entire study population had breast cancer. The univariate analysis suggested that older age $(p=0.002)$ and presence of suspicious lumps $(p<0.001)$ were significantly associated with malignancy. In contrast, presence of bloody discharge was not significantly associated with malignancy $(p=0.324)$. The multivariate analysis confirmed that older age $(p=0.023)$ and presence of suspicious lumps $(p<0.001)$ were independent predictors of malignancy. For patients without suspicious lumps, we did not observe any association between the presence of bloody discharge and malignancy. For patients with suspicious lumps, tumor size was significantly associated with malignancy $(p<0.001)$. Conclusion: Our study suggests that older age and the
\end{abstract}

Correspondence to: Kai Chen: Guangdong Provincial Key Laboratory of Malignant Tumor Epigenetics and Gene Regulation, Sun Yat-Sen Memorial Hospital, Sun Yat-Sen University, Guangzhou, P.R. China. E-mail: chenkai23@mail.sysu.edu.cn and Fengxi Su, Guangdong Provincial Key Laboratory of Malignant Tumor Epigenetics and Gene Regulation, Sun Yat-Sen Memorial Hospital, Sun Yat-Sen University, Guangzhou, P.R. China. E-mail: sufengxi@mail.sysu.edu.cn

Key Words: Predictors of malignancy, nipple discharge. presence of suspicious lumps are predictors of the presence of malignancy in females with suspicious $N D$.

Nipple discharge (ND) is commonly seen in female patients in daily breast clinics (1). There are benign and malignant causes of ND, including intraductal papilloma, ductal ectasia, pituitary adenomas, breast abscesses/infections, or breast cancer. Usually, ND presents as non-spontaneous or multiductal and had been considered as a physiological phenomenon for which observation alone was adequate, based on the National Comprehensive Cancer Network guidelines (2). Of patients with suspicious ND, namely discharge that is spontaneous, persistent, unilateral, single duct, or serosanguinous, up to $15 \%$ have malignant disease (3). Other studies suggest that the probability of breast cancer is between $9.3 \%$ and $21.3 \%$ in these patients $(4,5)$. Therefore, standard evaluations such as obtaining complete medical history, physical examination, ultrasonography, mammography or even core needle biopsy (CNB) are needed for diagnosis. For patients without suspicious lumps, selective duct excision (68) should be considered for definitive diagnosis.

However, the preoperative clinical predictors for malignancy in these patients are still unclear. In this retrospective study, we studied predictors of malignancy in female patients with suspicious ND. We believe that these predictors may be helpful for clinical decision making and patient consulting.

\section{Materials and Methods}

Patients. We extracted the relevant clinicopathological information from our electronic database (REDcap). Medical records, radiological imaging and reports, histopathology, cytology reports and surgery records of all patients were reviewed. The inclusion and exclusion criteria for eligible patients were as follows: Patients visited our clinic and complained of a suspicious ND; patients received treatment for suspicious ND at our hospital between January 1st 2007 and December 31st 2014; surgical treatment was defined as selective duct excision. 
Table I. Patient characteristics and univariate analysis of predictors of malignancy.

\begin{tabular}{|c|c|c|c|c|}
\hline Patient characteristic & Total $(n=334), n$ & Benign $(n=274), n(\%)$ & Malignant $(\mathrm{n}=60), \mathrm{n}(\%)$ & $p$-Value \\
\hline Median age (range), years & $45(19-81)$ & 44 & 49 & $0.002 *$ \\
\hline \multicolumn{5}{|l|}{ Age } \\
\hline$<50$ Years & 236 & $201(85.2)$ & $35(58.3)$ & \multirow[t]{2}{*}{0.021} \\
\hline$\geq 50$ Years & 98 & $73(14.8)$ & $25(41.7)$ & \\
\hline \multicolumn{5}{|l|}{ Suspicious lumps } \\
\hline Absence & 163 & $148(54.0)$ & $15(25.0)$ & \multirow[t]{2}{*}{$<0.001 * *$} \\
\hline Presence & 171 & $126(46.0)$ & $45(75.0)$ & \\
\hline \multicolumn{5}{|l|}{ Bloody discharge } \\
\hline Absence & 164 & $138(50.4)$ & $26(43.3)$ & \multirow[t]{2}{*}{$0.324 * *$} \\
\hline Presence & 170 & $136(49.6)$ & $34(56.7)$ & \\
\hline \multicolumn{5}{|l|}{ Histology } \\
\hline \multicolumn{5}{|l|}{ Benign diseases } \\
\hline Papilloma & & $201(73.3)$ & & \\
\hline Ductal ectasia & & $52(19.0)$ & & \\
\hline Other & & $21(7.7)$ & & \\
\hline \multicolumn{5}{|l|}{ Malignant diseases } \\
\hline Invasive carcinoma & & & $24(40.0)$ & \\
\hline DCIS & & & $19(31.7)$ & \\
\hline Papillary carcinoma & & & $9(15.0)$ & \\
\hline DCIS with micro-invasion & & & $6(10.0)$ & \\
\hline Other & & & $2(3.3)$ & \\
\hline
\end{tabular}

DCIS: Ductal carcinoma in situ. *Mann-Whitney $U$-test; **Chi-square test.

Physical examination and radiological assessment (ultrasound with or without mammography) were performed prior to surgery. For patients with suspicious lumps (by physical examination or radiological assessment), CNB was conducted before surgery. When any evidence suggesting a malignancy was obtained preoperatively, the patient receive the standard-of-care for breast cancer treatment. When the results of CNB indicated benign disease, selective duct excision or ultrasound-guided vacuum-assisted biopsy were performed. For patients without clinically suspicious lumps, selective duct excision was conducted. For selective duct excision, we routinely began with identification of the secreting ducts by squeezing the nipple. We then inserted a blunt probe into the secreting ducts as an indicator. A $25-40 \%$ periareolar incision was then made; the indicated ducts were isolated and resected from the nipple to the retromammary space with preservation of the surrounding ducts. Surgical reconstruction of the mammary gland was performed after the excision. This retrospective study used deidentified information from the available dataset, and waived the need for ethical approval and patients' informed consent, based on our institutional policy. The Authors had no ways of identifying the patients included in this study.

Statistical analysis. All the statistical analysis of the study data was carried out using STATA 13.0 (Stata Corp LP, College Station, TX, USA). Descriptive statistics are reported as the median and interquartile range or frequency with percentage. Nominal variables were compared using chi-squared tests. Continuous variables were compared using the Wilcoxon rank-sum test. Multivariable logistic regression analysis was used for multivariate analysis. For all the statistical analyses, a value of $p<0.05$ was considered to be statistically significant.

\section{Results}

Three hundred and thirty-four patients were eligible and included in this study. All underwent selective duct excision. Amongst them, 18.0\% (60/334) were diagnosed with breast cancer. The median age of the study population was 45 (range, 19-81) yrs. The histology of the malignancy of the 60 patients is given in Table I. The major histological characterization of the 274 patients with benign lesions was intraductal papilloma $(201 / 274 ; 73.3 \%)$.

The univariate analysis (Table I) suggested that older age $(p=0.002)$ and presence of suspicious lumps $(p<0.001)$ were significantly associated with malignancy. In contrast, the presence of bloody discharge was not significantly associated with malignancy $(p=0.324)$. Multivariate analysis confirmed that older age ( $\geq 50$ years) and presence of suspicious lumps were independent predictors of malignancy (Table II).

For the 163 patients without suspicious lumps (Table III), we did not observe any association between the presence of bloody discharge and malignancy. The proportions of patients with malignancy were $10.5 \%(9 / 86)$ and $7.8 \%(6 / 77)$ in patients with and without bloody discharge $(p>0.05)$, respectively. The distribution of histology was not associated with the presence of bloody discharge.

For the 171 patients with suspicious lumps (Table IV), the tumor size was significantly associated with malignancy $(p<0.001)$. The mean size of malignant lumps was 
Table II. Multivariate analysis of predictors of malignancy.

\begin{tabular}{lccc}
\hline Patient characteristic & Total no. & HR $(95 \% \mathrm{CI})$ & $p$-Value \\
\hline Age & & & \\
$\quad<50$ Years & 236 & 1 & 0.023 \\
$\quad \geq 50$ Years & 98 & $1.97(1.94-6.93)$ & \\
$\quad \begin{array}{l}\text { Suspicious lumps } \\
\quad \text { Absence }\end{array}$ & 163 & 1 & $<0.001$ \\
$\quad$ Presence & 171 & $3.67(1.94-6.93)$ & \\
\hline
\end{tabular}

CI: Confidence interval; HR: hazard ratio.

significantly larger than that of benign lumps $(2.1 \mathrm{vs} .1 .1 \mathrm{~cm}$, $p<0.001$ ). Additionally, higher BI-RADs category (BI-RADs $4-5)$ was significantly associated with malignancy $(p<0.001)$

\section{Discussion}

Nipple discharge is a common symptom in the breast clinic. Suspicious ND usually presents as spontaneous, unilateral, persistent, bloody and secreting from a single duct (9-11). Patients with suspicious ND require further examination or surgical treatment to rule out the possibility of breast cancer. At our institution, the standard evaluation for these patients includes a thorough history and physical examination; ultrasonography and mammography may be performed depending on the age of the patient. Ultrasonography or mammography along with CNB is considered for patients with ipsilateral and suspicious breast lumps. For those without imaging abnormalities, or those with benign histology by $\mathrm{CNB}$, subareolar duct excision is the standard management for definitive diagnosis (6-8).

Numerous studies have been conducted to determine the optimal management strategy for these patients. Currently, there are no proven predictive models for malignancy in these patients. Surgical selective duct excision still remains the gold standard for treatment $(3,5,12,13)$. In our study, $18 \%$ of all cases (60/344) were confirmed to have malignancy. In the 163 patients without suspicious lumps, 15 (9.2\%) had malignancy. The risks of breast cancer in patients with and without suspicious lumps found here were similar to those of previous reports $(3,5,14,15)$.

Patients with older age were more likely to have malignancy, as shown in our study. This is consistent with previous studies, indicating that the incidences of breast cancer were generally higher in elderly women. However, previous studies did not suggest any association between the color of the ND (serous, serosanguinous or colored discharge) and the presence of malignancy (16). Additionally, the association between bloody discharge and an increased risk of breast cancer was also controversial (6,
Table III. Distributions of the histology subtypes between patients with and without bloody discharge.

\begin{tabular}{lccc}
\hline Histology & \multicolumn{2}{c}{ Bloody discharge, $\mathrm{n}(\%)$} & \multirow{2}{*}{$p$-Value } \\
\cline { 2 - 3 } & $\begin{array}{c}\text { Presence } \\
(\mathrm{n}=86)\end{array}$ & $\begin{array}{c}\text { Absence } \\
(\mathrm{n}=77)\end{array}$ & \\
\hline Bengin & & & 0.377 \\
$\quad$ Papilloma & $50(58.1)$ & $49(63.6)$ & \\
$\quad$ Ductal ectasis & $22(25.6)$ & $16(20.8)$ & \\
Other & $5(5.8)$ & $6(7.8)$ & \\
Malignant & & & 0.668 \\
DCIS & $5(5.8)$ & $5(6.5)$ & \\
Invasive & $4(4.7)$ & $0(0.0)$ & \\
DCIS with micro-invasion & $0(0.0)$ & $1(1.3)$ & \\
\hline
\end{tabular}

DCIS: Ductal carcinoma in situ.

Table IV. Relationship between breast lumps and pathological results.

\begin{tabular}{lccc}
\hline & $\begin{array}{c}\text { Benign } \\
(\mathrm{n}=126) \mathrm{n}(\%)\end{array}$ & $\begin{array}{c}\text { Malignancy } \\
(\mathrm{n}=45) \mathrm{n}(\%)\end{array}$ & $p$-Value \\
\hline $\begin{array}{c}\text { Tumor size } \\
\text { Mean, cm }\end{array}$ & 1.1 & & \\
$<1 \mathrm{~cm}$ & $70(55.6)$ & $10(22.2)$ & $<0.001$ \\
$\geq 1 \mathrm{~cm}$ & $56(44.4)$ & $35(77.8)$ & \\
BI-RADS & & & \\
$1-3$ & $239(87.3)$ & $21(35.0)$ & $<0.001$ \\
$4-5$ & $35(12.7)$ & $39(65.0)$ & \\
\hline
\end{tabular}

BI-RADs: Breast imaging reporting and data system (2).

17). In our study, we did not observe any association between bloody ND and an increased risk of having breast cancer, which is not consistent with previous studies. Some studies suggest that breast lesions other than breast cancer may also lead to bloody ND. We suggest that for patients with bloody ND, caution is required and surgical treatment is indicated. Additionally, we noted that the presence of suspicious lumps were associated with malignancy. Patients with suspicious lumps larger than $1 \mathrm{~cm}$ had significantly higher risk of breast malignancy than those with smaller suspicious lumps $(38.5 \%$ vs. $12.5 \%)$. For patients with suspicious lumps, standard CNB is necessary for pathological treatment.

In conclusion, a total of $18 \%$ of female patients with suspicious ND in this study had malignant disease. Older age and the presence of suspicious lumps, rather than the presence of bloody discharge, were significantly associated with malignancy. 


\section{Ethical Approval and Consent to Participate}

This retrospective study used de-identified information from available dataset, and waived the need for ethical approval and patients' informed consents, based on our institutional policy. The Authors had no way to identify the patients included in this study.

\section{Availability of Data and Material}

The datasets used and analyzed during the current study are available from the corresponding Author on reasonable request.

\section{Conflicts of Interest}

The Authors declare that they have no competing interests in regard to this study.

\section{Funding}

This study was supported by the National Natural Science Foundation of China (Grant\# 81402201, Grant\#81372817), National Natural Science Foundation of Guangdong Province (Grant\# 2014A030310070), and Grant (2013) 163 from the Key Laboratory of Malignant Tumor Molecular Mechanism and Translational Medicine of Guangzhou Bureau of Science and Information Technology.

\section{References}

1 Sakorafas GH: Nipple discharge: current diagnostic and therapeutic approaches. Cancer Treat Rev 27: 275-282, 2001.

2 NCCN: Breast cancer screening and diagnosis. In: http://www.ncen.org, 2016.

3 Morrogh M, Park A, Elkin EB and King TA: Lessons learned from 416 cases of nipple discharge of the breast. Am J Surg 200: 73-80, 2010.

4 King TA, Carter KM, Bolton JS and Fuhrman GM: A simple approach to nipple discharge. Am Surg 66: 960-965; discussion 965-966, 2000.

5 Montroni I, Santini D, Zucchini G, Fiacchi M, Zanotti S, Ugolini G, Manaresi A and Taffurelli M: Nipple discharge: Is its significance as a risk factor for breast cancer fully understood? Observational study including 915 consecutive patients who underwent selective duct excision. Breast Cancer Res Treat 123: 895-900, 2010.
6 Adepoju LJ, Chun J, El-Tamer M, Ditkoff BA, Schnabel F and Joseph KA: The value of clinical characteristics and breastimaging studies in predicting a histopathologic diagnosis of cancer or high-risk lesion in patients with spontaneous nipple discharge. Am J Surg 190: 644-646, 2005.

7 Alcock C and Layer GT: Predicting occult malignancy in nipple discharge. ANZ J Surg 80: 646-649, 2010.

8 Dupont SC, Boughey JC, Jimenez RE, Hoskin TL and Hieken TJ: Frequency of diagnosis of cancer or high-risk lesion at operation for pathologic nipple discharge. Surgery 158: 988-995, 2015.

9 Ouldamer L, Kellal I, Legendre G, Ngo C, Chopier J and Body G: Management of breast nipple discharge: Recommendations. J Gynecol Obstet Biol Reprod (Paris) 44: 927-937, 2015 (in French).

10 Vargas HI, Romero L and Chlebowski RT: Management of bloody nipple discharge. Curr Treat Options Oncol 3: 157-161, 2002.

11 Vargas HI, Vargas MP, Eldrageely K, Gonzalez KD and Khalkhali I: Outcomes of clinical and surgical assessment of women with pathological nipple discharge. Am Surg 72: 124-128, 2006.

12 Yang L, Wu D and Fan ZM: Retrospective analysis of pathologic nipple discharge. Genet Mol Res 14: 1443-1449, 2015.

13 Yin WJ, Di GH, Liu GY, Wu J, Lu JS, Han QX, Shen ZZ and Shao ZM: Clinicopathological features of breast cancer patients with nipple discharge. Mol Med Rep 3: 863-868, 2010.

14 Arleo EK, Reichman M, Dashevsky BZ, Babagbemi K and Drotman M: Breast cancer in women in their thirties (20072013): A retrospective review. Breast Dis 35: 87-93, 2015.

15 Nelson RS and Hoehn JL: Twenty-year outcome following central duct resection for bloody nipple discharge. Ann Surg 243: 522-524, 2006.

16 Dixon JM and Mansel RE: ABC of breast diseases. Symptoms assessment and guidelines for referral. BMJ 309: 722-726, 1994.

17 Dinkel HP, Gassel AM, Muller T, Lourens S, Rominger M and Tschammler A: Galactography and exfoliative cytology in women with abnormal nipple discharge. Obstet Gynecol 97: 625-629, 2001.
Received May 2, 2017

Revised June 5, 2017

Accepted June 6, 2017 